\title{
Endovascular treatment of scalp cirsoid aneurysms
}

\author{
A. K. Gupta, S. Purkayastha, N. K. Bodhey, T. R. Kapilamoorthy, T. Krishnamoorthy, C. Kesavadas, \\ B. Thomas \\ Department of Imaging Sciences and Interventional Radiology, Sree Chitra Tirunal Institute of Medical Sciences and Technology, Trivandrum, \\ Kerala, India
}

\begin{abstract}
Background: Scalp is the most common site of soft tissue arteriovenous fistulae and surgical excision has been the primary mode of treatment. Endovascular treatment has evolved as an alternative to the surgery. Aims: To evaluate the effectiveness of percutaneous direct-puncture embolization of cirsoid aneurysms. Materials and Methods: From January 1995 to December 2004, 15 patients underwent percutaneous direct-puncture embolization of cirsoid aneurysms. Plain X-ray, computerized tomography scan and complete selective cerebral angiogram were done in all. Seven patients had forehead lesions, four had temporal and the remaining four patients had occipital region cirsoid aneurysms. Lesions were punctured with 21-gauge needle and embolized with $20-50 \%$ cyanoacrylate-lipiodol mixture. Circumferential compression was applied during injection. Results: Post-embolization angiogram showed complete obliteration in 11 patients. The remaining four patients required adjunctive transarterial embolization with polyvinyl alcohol particles for complete lesion devascularization. Two patients had post procedure surgery for removal of disfiguring and hard glue cast. There were no major procedure-related complications. No patients had any recurrence in the followup. Conclusion: Percutaneous direct puncture embolization of cirsoid aneurysms is a safe and effective procedure. It can be effectively used as an alternative to surgery. Sometimes adjunctive transarterial embolization is also required to deal with deeper feeders.
\end{abstract}

Key words: Angiogram, cirsoid aneurysms, embolization, percutaneous direct puncture

Arteriovenous fistulae were first described by Hunter in 1757. ${ }^{[1]}$ The term cirsoid aneurysm was applied to vascular malformations of the scalp in 1833 by Brecht. ${ }^{[1]}$ The malformation is drained by enlarged, tortuous veins, which may, in parts, show variceal dilatation. Various names have been used to describe these lesions like aneurysma cirsoide, aneurysma serpentinum, aneurysma racemosum, plexiform angioma, arteriovenous fistula, arteriovenous aneurysm and arteriovenous malformation. ${ }^{[2,3]}$ With the development of endovascular obliteration of the malformation, there has been renewed interest in these lesions. ${ }^{[4-7]}$ The purpose of this study is to describe our experience with embolization of cirsoid aneurysms in 15 patients.

\section{Materials and Methods}

Clinical details of the patients treated between January 1992 and December 2004 were collected. Fifteen consecutive patients (nine male and six female patients; age range, 7-59 years) with scalp cirsoid aneurysms were treated with direct puncture and the injection of NBCA (Histoacryl-Blue; Braun, Melsungen, Germany) mixed with iodized oil (Lipiodol; Laboratoire Guerbet, Roissy, France). Transarterial embolization was also done as an adjunct to direct puncture embolization in few of them. Our institutional review board approved the procedure. Informed consent was obtained from each patient.

All 15 patients presented with pulsatile scalp mass. Four patients (three with parietal and one with an occipital scalp lesion) had local bleeding from the lesion. Nine patients complained of tinnitus, seven patients had focal headache. On examination, in all patients, obvious, pulsatile swellings of the scalp, with dilated vessels leading into the lesion and an audible bruit on auscultation, were encountered. Seven patients had forehead lesions in the frontoparietal region and four of them had an associated temporal region swelling. Four patients had isolated temporal region pulsatile swelling and in four patients the lesion was confined to the occipital region only. The size varied from $2 \times 2$ to $6 \times 6 \mathrm{~cm}$. Compression of the ipsilateral carotid or the main feeding vessel caused the lesion to decrease in size and diminished the bruit. In three patients, lesions involving the forehead region were thought to be traumatic in origin, with a history of head trauma 
five to seven years ago. In the other 12 patients, the lesions were spontaneous or congenital. Three patients had previously undergone partial excision of their lesion and/or ligation of the feeding arteries. In all these patients, a collateral arterial supply to the lesion had subsequently been recruited. The lesions were supplied by the contralateral external carotid arteries via collateral vessels.

Plain X-ray and CT scan of head in all patients showed soft tissue scalp swelling, no intracranial lesion was demonstrated. All patients underwent complete cerebral angiography with bilateral selective internal and external carotid injections to document the location, size, feeding arteries and venous drainage of the lesions. The forehead lesions in seven patients were supplied by combinations of superficial temporal, internal maxillary artery and middle meningeal arteries. Two of them had associated supply from facial artery and twigs from ophthalmic arteries. Temporal region lesions were supplied by superficial temporal arteries, middle meningeal artery and deep temporal arteries. The occipital scalp lesions were supplied bilaterally by the occipital arteries. Posterior auricular arteries also supplied in a few of them. In two patients bilateral vertebral angiography demonstrated opacification of the lesions through direct supply and communication with the occipital artery. In all patients, multiple sites of arteriovenous communication were identified at selective angiography and in no case a single-hole fistula was seen. No intracranial arteriovenous malformation was observed in any patient.

\section{Technique of embolization}

\section{Direct-puncture embolization}

Procedure was performed under local anesthesia. After selective transarterial angiography, the lesions were punctured in the area nearest to the arteriovenous connection and direct angiography was performed with and without manual compression of the venous drainage in the region. In patients in whom a glomuslike nidus was visualized at angiography, this area of arteriovenous connection was punctured [Figure 1]. In patients in whom the lesion was extensive and the venous channels were engorged, the venous channel adjacent to the nidus was punctured and embolized [Figures 2 and 3]. To achieve circumferential flow reduction around the lesion, we used a sterilized rounded or oval-shaped metallic ring held in place over the dilated collecting vein with rubber bands. The lesion was punctured by using a 21-gauge butterfly needle. Contrast material injected through this needle showed no distal escape beyond the edge of the metallic ring, indicating adequate venous compression. When more pressure was applied to the metallic ring, the arterial inflow could also be reduced, thereby achieving complete flow reduction in the desired area. With the

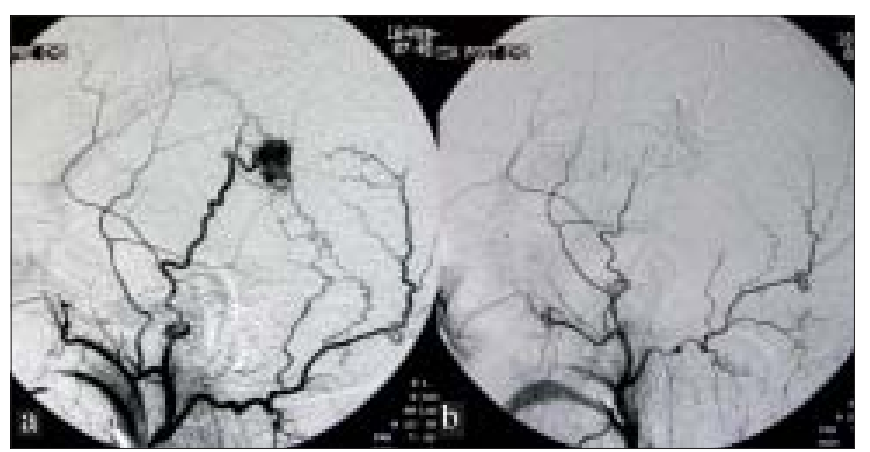

Figure 1: Case 5. This 22-year-old male presented with headache, tinnitus and right parietal pulsatile swelling of $3 \times 3 \mathrm{~cm}$ in diameter. (a) Right ECA angiogram revealed glomus type nidus with supply from superficial temporal and occipital arteries. (b) Percutaneous injection of $20 \%$ cyanoacrylate (NBCA) $(1.4 \mathrm{ml})$ into the nidus caused complete occlusion

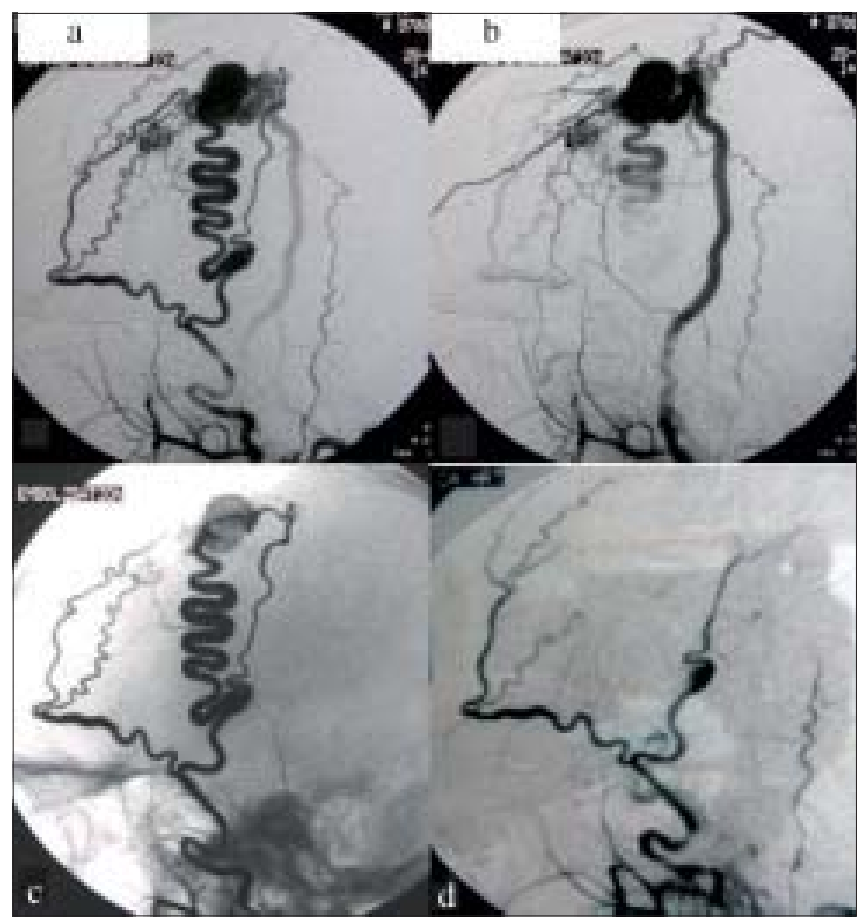

Figure 2: Case 7. This 45-year-old female presented with headache and left parietotemporal $5 \times 4 \mathrm{~cm}$ swelling. $(a, b, c)$ Left ECA angiogram revealed supply from superficial temporal artery (STA) and middle meningeal artery (MMA). (d) Percutaneous injection of 40\% NBCA (2.2 $\mathrm{ml}$ ) in the venous sac caused complete devascularization

ring held in place, cyanoacrylate-lipiodol mixture was injected into the nidus or the collecting vein. The metallic ring was left in place for a few minutes and then removed gradually. The operators' hands compressed the frontal and angular veins in a few cases where the compression by the metallic ring was not possible. The concentration of the NBCA-iodized oil mixture was adjusted according to the flow rate as evaluated at angiography and the injection rate and volume were controlled by using fluoroscopic road mapping during NBCA injections. Repeated puncture and injections were performed when residual lesion was demonstrated at post-embolization angiography or in large lesions [Figure 4]. 


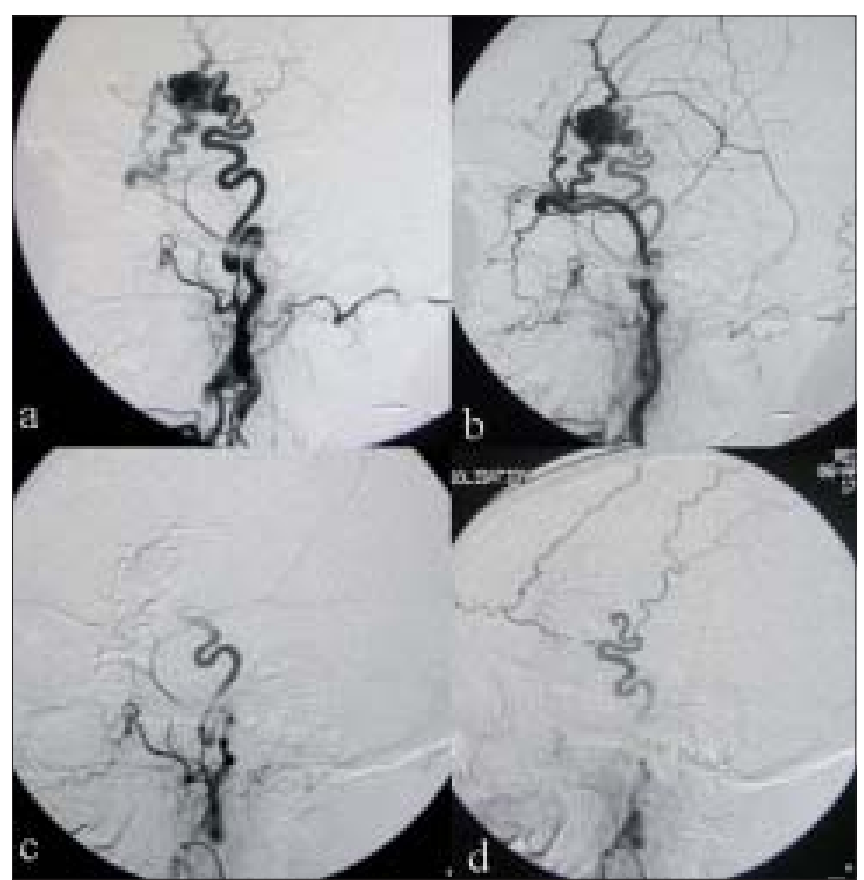

Figure 3: Case 11. (a, b) This 37-year-old male presented with tinnitus and right temporal cirsoid aneurysm supplied by right STA and internal maxillary arteries. (c, d) Percutaneous injection of 25\% NBCA (1.8 ml) into the nidus and venous component caused complete disappearance of the lesion

\section{Transarterial embolization}

This was performed as an adjunct to direct puncture when the supply from deeper arteries was seen in the lesions. Transarterial embolization using polyvinyl alcohol particles, gelfoam soaked in alcohol and NBCA was performed for supply from middle meningeal artery, internal maxillary artery, deep temporal artery and posterior auricular arteries.

Experienced interventional radiologists were involved in the procedures, retrieval of data and image analysis. Post-procedure assessments were done on the next day of the procedure, at one month and then every six-monthly. All the patients were clinically examined to detect any recurrent swelling, audible bruit etc. Follow-up angiograms were not considered until there was clinical suspicion of recurrence.

\section{Results}

Post-embolization angiograms showed that in 11 patients the lesion had completely disappeared after single or multiple percutaneous injections. Two to six percutaneous injections were needed for complete obliteration. Total volume of cyanoacrylate injected ranged from 1.2 to $6 \mathrm{ml}$. After cyanoacrylate injection in two patients with a forehead lesion, the blood supply to the lesions from the ophthalmic arteries ceased completely. In four patients, the lesion was more than 90\% devascularized. The first two were involved in the forehead as well as temporal region lesions and the last two arteries in occipital lesions. The feeders were identified and embolized transarterially with polyvinyl alcohol particles of 250-355 $\mu$ size, gelfoam soaked in alcohol and NBCA. Total reduction of blush was achieved.

After percutaneous embolization, in two patients lesions were resected due to cosmetic reasons. Immediately after injection, thrombosis occurred in the lesions, which became swollen and hard. After embolization, most patients reported pain at the injection site. This pain, due to the glue injection, was managed effectively with intravenous administration of analgesics. In one patient with large occipital scalp lesion, a small amount of glue drained out of the lesion to the external jugular vein during injection. But it was clinically silent. There was no other procedure-related complication or delayed skin problems.

We have six months to 11 years follow-up in 13 patients. No patient had any recurrence of pain, swelling or tinnitus. There was no audible bruit in them. So there was no clinical suspicion of any recurrence and angiogram was not repeated in them.

\section{Discussion}

A cirsoid aneurysm of the scalp is an abnormal fistulous connection between the feeding arteries and draining veins, without an intervening capillary bed. ${ }^{[8]}$ Soft tissue arteriovenous fistulae occur most commonly in the scalp. Although only $14 \%$ of the body surface area is in the head, $50 \%$ of the integument arteriovenous fistulae occur in this region..$^{[9]}$ When these abnormal fistulae enlarge to a size that is clinically recognizable and there are large, dilated draining veins, the lesions are termed cirsoid aneurysms. ${ }^{[10]}$

Most congenital lesions become symptomatic in the third decade of life (range, three months to 59 years of age). Sixty per cent of the affected persons are male. The location of scalp cirsoid aneurysms is roughly evenly distributed among the frontal, temporal and parietal regions. ${ }^{[2]}$

Although controversy still exists regarding the cause of these lesions, it is generally accepted that they may be either of congenital or traumatic origin. In our series, $20 \%$ of the lesions could be directly related to trauma (blunt, non-penetrating trauma in the majority). Penetrating trauma as a cause is well described, including iatrogenic-induced fistulae after hair transplantation, arthroscopy of the temporomandibular joint and craniotomy for intracranial procedures. ${ }^{[11-17]}$ Congenital malformations are more frequent and constituted $80 \%$ in our series. Theories about their occurrence include persistence of primitive arteriovenous fistulae. ${ }^{[18]}$ Familial scalp fistulae are extremely rare..$^{[2,3]}$

Almost all patients present with a scalp swelling that has gradually increased in size from birth or after head 


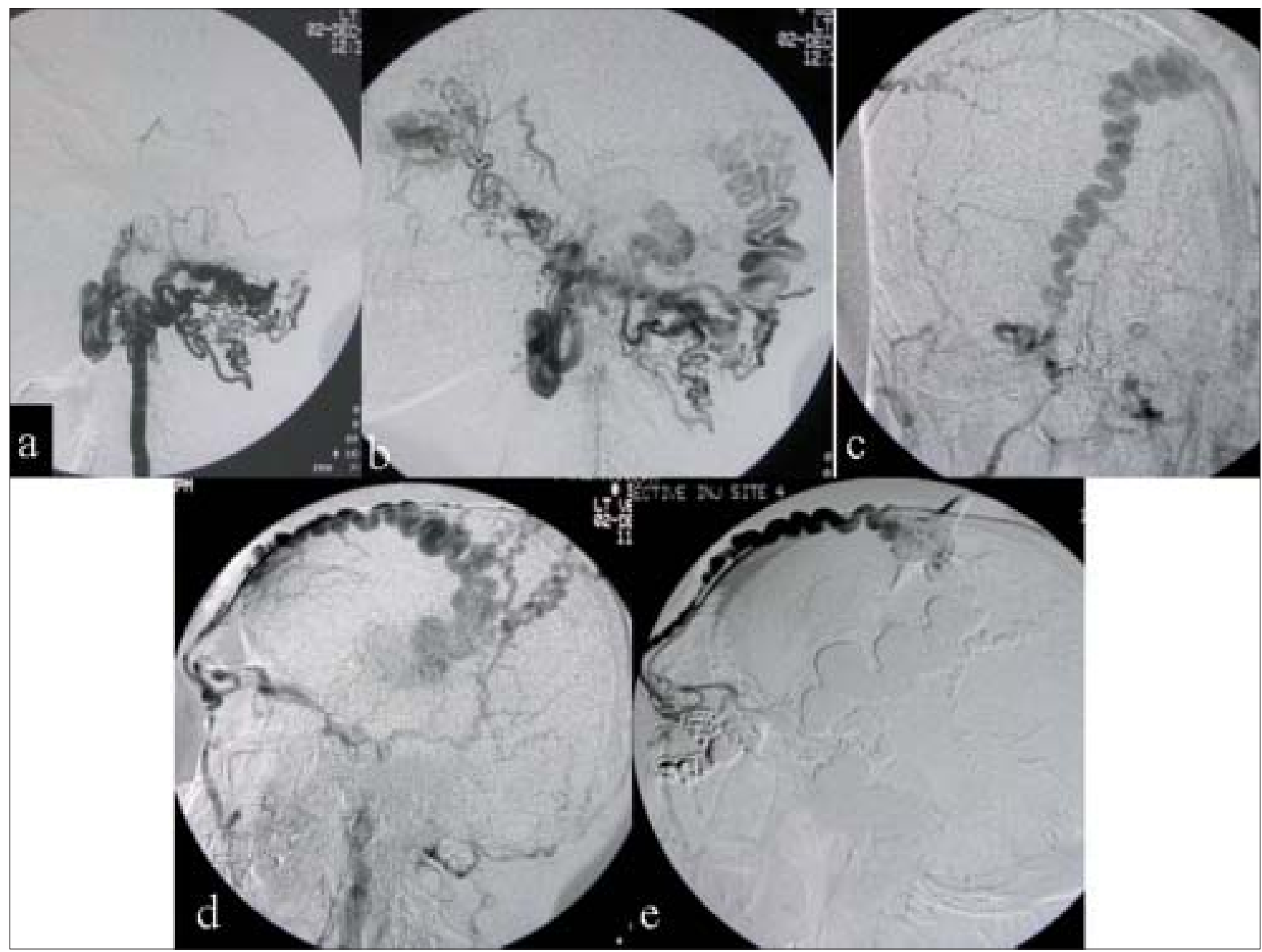

Figure 4: Case 14. This 67-year-old male had previous surgical ligation of external carotid artery (ECA) branches and had tinnitus and recurrent pulsatile swelling over right forehead, temple and occipital region seven years after surgery. (a, b, c, d) Angiogram revealed supply from vertebral artery and bilateral ECA branches. (e) Injection was done at four sites (total $4 \mathrm{ml}$ ) with $30 \%$ NBCA showed complete devascularization. Patient underwent surgery for glue cast removal

trauma. Rapid increases in size have been reported to occur at puberty, during menstruation and during pregnancy. ${ }^{[19]}$ Associated symptoms and signs include pain, throbbing headaches and bruits. ${ }^{[19]}$ Hemorrhage from the lesion is uncommon. ${ }^{[20]}$ Large lesions have also been associated with scalp necrosis. ${ }^{[20]}$ Vascular endothelial growth factor is expressed by these lesions and is responsible for their continuous growth. ${ }^{[21]}$ Rarely, they can present with epilepsy. ${ }^{[22]}$

The diagnosis is clinical in the majority of patients. Angiography is undertaken to delineate the lesion and to exclude an intracranial component. ${ }^{[23]}$ This takes the form of an enlarged middle meningeal artery with fine feeding vessels running through the bone feeding the malformation. ${ }^{[3]}$ Yokouchi et al. classified scalp arteriovenous fistulae into three types: Type A: has a single fistulous connection from the proximal portion of the artery, Type B: has a single fistulous connection but from multiple distal portions of the arteries and Type C: where there are multiple fistulae constituting the plexiform feeding type. ${ }^{[24]}$ Sometimes the drainage can be intracranial with an associated cerebral arteriovenous malformation. ${ }^{[25]}$ The diagnosis of scalp cirsoid aneurysm and its differentiation from sinus pericranii can be difficult and some confusion between the two types of lesions exists in the literature. Strictly speaking, sinus pericranii is a collection of non-muscular venous blood vessels tightly adhering to the outer surface of the cranium and communicating directly with a intracranial venous sinus via deploic veins. ${ }^{[25,26]}$

Indications for treatment are the prevention of hemorrhage, tinnitus and the cosmetic relief of the pulsatile swelling. Treatment options include surgical excision, ligation of the feeding vessels, transarterial and transvenous embolization, injection of sclerosant into the nidus and electrothrombosis. ${ }^{[4-7,27-32]}$

In the past, treatment of arteriovenous malformation of the scalp and face was primarily reliant on surgical excision or ligation of the feeding arteries. ${ }^{[26-30,33]}$ Some 
lesions were so large that excision was not possible. ${ }^{[34]}$ Ligation of feeding arteries has been particularly troublesome because of the recruitment of a collateral vessel supply and the loss of access to the fistula for further embolization. ${ }^{[35]}$ Transarterial and transvenous embolization of scalp cirsoid aneurysms has been used as an adjunct to surgery or as definitive therapy. ${ }^{[35,36]}$ Embolization alone could remedy a scalp arteriovenous fistula and improve the grotesque feature without scalp ischemia. ${ }^{[4,6]}$

In cases of a cirsoid aneurysm of the scalp, directpuncture embolization with NBCA, absolute alcohol or a metallic thrombogenic coil has been reported. ${ }^{[37,38]}$ In direct-puncture embolization, the targeted vessel is the venous structure just distal to the arteriovenous connection. Occlusion of the vascular structures with this technique thus involves no risk of ischemic skin complications. Immediate venous occlusion allows continuous redistribution of the embolic agent to adjacent vascular spaces and effective devascularization occurs without complications. During treatment with NBCA embolization by means of direct puncture in the 15 consecutive patients in our series, there were no complications involving puncture of the lesion, occlusion of venous channels or abrupt occlusion and thrombosis of the nidus.

For temporary occlusion of the venous outflow, elastic ring, elastic strap, a ring-shaped compression device can be used, thus avoiding exposure of the operator's hand to radiation. In this series, multiple directpuncture angiographies were followed by adjustment of compression points and venous channels were thus completely occluded. We are using this technique since 1995. Recently Duncan et al. described it as 'cookiecutter technique. ${ }^{[39]}$

In most lesions, a large, high-flow arteriovenous fistula often is associated with the aneurysm and the embolus must, therefore, be large; otherwise, the embolus may pass into the pulmonary circulation. Temporary manual compression of the venous drainage during NBCA injection slows down the blood flow and can prevent inadvertent washout into the distal venous outflow tract and pulmonary circulation. We have not encountered any pulmonary embolism related to the procedure.

Lodging of embolic materials like coils in proximal feeding vessels lessens the blood supply and has been a helpful adjunct to surgery but rarely is curative. ${ }^{[4,6]}$ Recent developments in the design of microcatheters and distal navigation techniques have made possible the catheterization of feeding arteries close to the nidus. Injection of NBCA with a microcatheter wedged into the nidus may lead to permanent devascularization of an arteriovenous malformation without risk of ischemia of the adjacent normal tissue. But total devascularization involving transarterial embolization of the multiple feeding arteries may, however, be ineffective or technically difficult. So transarterial route of embolization can only be used as an adjunct to directpuncture embolization of cirsoid aneurysms.

\section{Conclusion}

Percutaneous direct-puncture embolization of cirsoid aneurysms is a safe and effective procedure. It can be effectively used as an alternative or adjunct to surgery. Sometimes adjunctive transarterial embolization is also required to deal with deeper feeders.

\section{References}

1. Elkin DC. Cirsoid aneurysm of the scalp with the report of an advanced case. Ann Surg 1924;80:332-40.

2. Khodadad G. Familial cirsoid aneurysms of the scalp. J Neurol Neurosurg Psychiatry 1971;34:664-7.

3. Khodadad G. Arteriovenous malformations of the scalp. Ann Surg 1973;177:79-85.

4. Barnwell SL, Halbach VV, Dowd CF, Higashida RT, Hieshima GB. Endovascular treatment of scalp arteriovenous fistulas associated with a large varix. Radiology 1989;173:533-9.

5. Djindjian R, Cophignon J, Theron J, Merland JJ, Houdart R. Embolization by superselective angiography from the femoral route in neuroradiology: Review of 60 cases. Neuroradiology 1973;6:20-6.

6. Kasdon DL, Altemus LR, Stein BM. Embolization of a traumatic arteriovenous fistula of the scalp with radiopaque gelfoam pledgets. J Neurosurg 1976;44:753-6.

7. Mourao GS, Hodes JE, Gobin YP, Casasco A, Aymard A, Merland JJ. Curative treatment of scalp arteriovenous fistula by direct puncture and embolization with absolute alcohol. J Neurosurg 1991;75:634-7.

8. Rappaport I, Yim D. Congenital arteriovenous fistulas of the head and neck. Arch Otolaryngol 1973;97:350-3.

9. Watson WL, Mc Carthy WD. Blood and lymph vessels tumors: A report of 1056 cases. Surg Gynecol Obstet 1940;71:569-98.

10. Newton TH, Trost BT. Arteriovenous malformations and fistulae. In: Newton TH, Potts DG, editors. Radiology of the skull and brain. Vol2, book 4, Angiography. St Louis: Mosby; 1974. p. 2502-65.

11. Badejo L, Rockwood P. Traumatic arteriovenous fistula of the scalp. J Neurosurg 1987;66:773-4.

12. Barros D'sa AA, Heard GE. Arteriovenous fistula after hair transplantation. Br Med J 1978;1:340-1.

13. Lanzieri CF, Sacher M, Som PM, Haimov M. Arteriovenous fistula after hair transplantation. AJNR Am J Neuroradiol 1985;6:111-2.

14. Semashko DC, Schwartz ME, Kaynan A, Harrington EB. Arteriovenous fistula following punch-graft hair transplantation. J Dermatol Surg Oncol 1989;15:754-5.

15. Williams LR, Robinson JK, Yao JS. Hair transplantation producing arteriovenous fistulization. Ann Vasc Surg 1986;1:241-3.

16. Preisler SA, Koorbusch GF, Olson RA. An acquired arteriovenous fistula secondary to temporomandibular joint arthroscopy. J Oral Maxillofac Surg 1991;49:187-90.

17. Morioka T, Nishio S, Hikita T. Traumatic arteriovenous fistulae of the scalp at the area of previous craniotomy. Surg Neurol 1988;30:404-7.

18. Maroun FB, Jacob JC, Markesteyn TH, Mercer DR. Congenital venous malformation of the scalp associated with plexiform neurofibroma and cranial defect. J Neurosurg 1969;31:465-7.

19. Dandy W. Arteriovenous aneurysms of the scalp and face. Arch Surg 1946;52:1-32.

20. Malan E, Azzolini A. Congenital arteriovenous malformations of the face and scalp. J Cardiovase Surg 1968;9:109-37.

21. Matsushige T, Kiya K, Satoh H, Mizoue T, Kagawa K, Araki H. Arteriovenous malformation of the scalp: Case report and review of the literature. Surg Neurol 2004;62:253-9.

22. Mohanty S, Rao CJ. A large cirsoid aneurysm of the scalp associated 
with epilepsy. J Neurol Neurosurg Psychiatry 1976;39:835-6.

23. Verbiest H. Results of artificial slow flow angiography with arteriovenous aneurysms in the supply area of the external or internal carotid arteries. AJR Am J Roentgenol 1972;116:1-15.

24. Yokouchi T, Iwabuchi S, Tomiyama A, Samejima H, Ogata N, Goto. Embolization of scalp AVF. Interv Neuroradiol 1999;5:115-20.

25. Lanzino G, Passacantilli E, Lemole GM Jr, McDougall C, Spetzler RF. Scalp arteriovenous malformation draining into the superior sagittal sinus associated with an intracranial arteriovenous malformation: Just a coincidence? Case report. Neurosurgery 2003;52:440-3.

26. Vinas FC, Valenzuela S, Zuleta A. Literature review: Sinus pericranii. Neurol Res 1994;16:471-4.

27. Muthukumar N, Rajagopal V, Manoharan AV, Durairaj N. Surgical management of cirsoid aneurysms. Acta Neurochir (Wien) 2002;144:349-56.

28. Nagasaka S, Fukushima T, Goto K, Ohjimi H, Iwabuchi S, Maehara F. Treatment of scalp arteriovenous malformation. Neurosurgery 1996;38:671-7.

29. Shenoy SN, Raja A. Scalp arteriovenous malformations. Neurol India 2004;52:478-81.

30. Brodie BC. An account of a case of aneurysm by anastomosis of the forehead treated by the application of ligatures. Med Chir Trans 1829; $15: 177-85$.

31. Han MH, Seong SO, Kim HD, Chang KH, Yeon KM, Han MC. Craniofacial arteriovenous malformation: Preoperative embolization with direct puncture and injection of n-butyl cyanoacrylate. Radiology 1999;211:661-6.
32. Gardner AMN, Stewart IA. Treatment of arteriovenous malformation by endarterial electrocoagulation. Br J Surg 1972;59:146-8.

33. Oldfield MC, Addison NV. Cirsoid aneurysms of the scalp. Br Med J $1962 ; 2: 23-4$

34. Dado DV, Stalnecker MC, Kernahan DA. Experience with electrothrombosis in the treatment of angiomas. Ann Plast Surg 1987;18;12-6.

35. Berenstein A, Scott J, Choi IS, Persky M. Percutaneous embolization of arteriovenous fistulas of the carotid artery. AJNR Am J Neuroradiol 1986:7:937-42.

36. Mathis JM, De Nardo AJ, Jensen ME, Lin KY, Dion JE. Arteriovenous fistulas of the scalp after hair transplantation treated by endovascular embolization. Ann Plast Surg 1994;33:633-7.

37. Mourao GS, Hodes JE, Gobin YP, Casaseo A, Aymard A, Merland JJ. Curative treatment of scalp arteriovenous fistulas by direct puncture and embolization with absolute alcohol. Report of three cases. J Neurosurg 1991;75:634-7.

38. Heilman CB, Kwan ES, Klucznik RP, Cohen AR. Elimination of a cirsoid aneurysm of the scalp by direct percutaneous embolization with thrombogenic coils: Case report. J Neurosurg 1990;73:296-300.

39. Duncan IC, Fourie PA. Circumferential flow reduction during percutaneous embolotherapy of extracranial vascular malformations: The "cookie-cutter" technique. AJNR Am J Neuroradiol 2003;24: $1453-5$.

Accepted on 11-03-2008

Source of Support: Nil, Conflict of Interest: None declared. 